\title{
PERBANDINGAN VISKOSITAS, TITIK NYALA DAN TITIK BEKU \\ BIODIESEL DARI RUMPUT LAUT (Eucheuma denticulatum), MINYAK IKAN LEMURU (Sardinellla longiceps) DAN BIODIESEL KOMERSIL
}

\section{THE COMPARISON OF VISCOSITY, FLASH POINT AND FREEZE POINT BIODIESEL OF SEAGRASS (Eucheuma denticulatum), SARDINELLA OIL (Sardinellla longiceps) AND COMMERCIAL BIODIESEL}

\author{
Andry Wijayanto, Boedi Setya Rahardja dan Woro Hastuti Satyantini
}

Fakultas Perikanan dan Kelautan Universitas Airlangga

Kampus C Mulyorejo - Surabaya, 60115 Telp. 031-5911451

\begin{abstract}
Necessity of fuel are increasing rapidly nowadays. But oil is an irreversible product, so it is required to look for other alternative fuels, especially from renewable materials. Currently being developed technology that uses biodiesel as renewable alternative fuel. The aim of this research to determine whether oil and seaweed Eucheuma denticulatum and Lemuru fish oil can be used as materials for biodiesel.

This research was conducted by observing and comparing the flash point, freeze point, and viscosity of each treatments. The Method in this research is experimental method and supported by panelist. There were 9 treatments in this study, there are P0 (Biodiesel commercial), P1 (Biodiesel Eucheuma denticulatum $100 \%$ ), P2 (Biodiesel Eucheuma denticulatum 75\% + Biodiesel commercial 25\%), P3 (Biodiesel Eucheuma denticulatum 50\% + Biodiesel commercial 50\%), P4 (Biodiesel Eucheuma denticulatum 25\% + Biodiesel commercial 75\%), P5 (Biodiesel Sardinella oil $100 \%$ ), P6 (Biodiesel Sardinella oil 75\% + Biodiesel commercial 25\%), P7 (Biodiesel Sardinella oil 50\% + Biodiesel commercial 50\%), and P8 (Biodiesel Sardinella oil 25\% + Biodiesel commercial 75\%). Each treatments was repeated 3 times. The main parameter observed was flash point, freeze point, and viscosity in every treatment. The data analysis used was non-parametric test with Friedman test and continued with Wilcoxon test.

The results of this study indicate that the best of the nine treatments is P8 which is a mixture of lemuru fish oil biodiesel $25 \%$ and $75 \%$ biodiesel with the specifications freezing point $-3^{\circ} \mathrm{C}$, viscosity of $4.02 \mathrm{~mm} 2 / \mathrm{s}$, and the flash point of $47.9^{\circ} \mathrm{C}$.
\end{abstract}

Keywords : Biodiesel, flash point, freeze point, viscosity, Eucheuma denticulatum and sardinella oil

\section{Pendahuluan}

Kebutuhan bahan bakar minyak saat ini semakin lama semakin meningkat, konsumsi bahan bakar yang terus menerus dan jumlah konsumsinya terus meningkat setiap tahunnya, tidak seimbang dengan ketersediaan bahan bakar minyak bumi di alam. Minyak bumi merupakan produk yang bersifat irreversible yang tidak dapat dikembalikan, sehingga perlu dicari alternatif bahan bakar lain terutama dari bahan yang terbarukan (Handayani, 2010).

Negara Indonesia merupakan negara yang mulai berkembang dalam bidang transportasi dan industri yang bergantung pada bahan bakar minyak. Menurut Darmanto (2006) ketergantungan akan kebutuhan bahan bakar minyak bumi dapat dikurangi dengan salah satu cara yang saat ini sedang dikembangkan yaitu teknologi biodiesel yang menggunakan bahan bakar alternatif dimana bahan bakunya masih sangat besar untuk dikembangkan.

Biodiesel merupakan monoalkil ester dari asam-asam lemak rantai panjang yang terkandung dalam minyak nabati atau lemak hewani untuk digunakan sebagai alternatif yang paling tepat guna menggantikan bahan bakar mesin diesel. Biodiesel bersifat biodegradable, dan hampir tidak mengandung sulfur. Biodiesel terbuat dari minyak nabati yang berasal dari sumber daya yang dapat diperbaharui (Rahayu, 2007). Biodiesel juga dapat diproduksi dari lemak hewan (Ozbay, 2008 dalam Murniati, 2011).

Menurut Atmadja (1996) Eucheuma denticulatum atau yang lebih dikenal dengan nama Eucheuma spinosum dalam dunia perdagangan adalah salah satu jenis rumput laut yang saat ini dapat dikembangkan sebagai bahan dasar biodiesel dari sektor perikanan 
dan kelautan yang memiliki potensi cukup luas dan belum termanfaatkan secara optimal. Salah satu contoh spesies rumput laut yang saat ini sedang dijadikan bahan pembuatan biodiesel yaitu Sargassum sp. karena dapat dimanfaatkan sebagai raw material untuk diolah menjadi bioetanol (Saputro dkk., 2012). Kandungan minyak nabati yang terdapat pada Eucheuma denticulatum sebesar 0,25\% (Atmadja dkk., 1996), sehingga tidak menutup kemungkinan Eucheuma denticulatum juga bisa dijadikan bahan pembuatan biodiesel.

Minyak ikan lemuru adalah minyak hewani yang merupakan hasil samping dari pabrik tepung ikan yang merupakan limbah dari pabrik pengalengan ikan (Murtidjo, 2001). Menurut Demirbas (2008) fish oil atau minyak ikan dapat dijadikan bahan dasar dalam pembuatan biodiesel. Kandungan minyak ikan yang kaya akan sterol yang disebut kolesterol dan juga ketersediaan minyak ikan lemuru yang melimpah dihasilkan dari pabrik pengalengan ikan di daerah Banyuwangi (Murtidjo, 2001), hal ini menjadi alasan minyak ikan lemuru dipilih untuk bahan pembuatan biodiesel karena minyak ikan lemuru merupakan bahan yang dapat diperbarui.

Menurut Siswani (2012), efisiensi biodiesel dapat diketahui dengan melakukan uji viskositas, titik beku, dan titik nyala. Penelitian ini dilakukan untuk mengetahui perbandingan efisiensi antara biodiesel komersil, biodiesel yang berasal dari rumput laut Eucheuma denticulatum, biodiesel dari minyak ikan lemuru, biodiesel campuran antara Eucheuma denticulatum dengan biodisel komersil dan biodiesel campuran antara biodiesel minyak ikan lemuru dengan biodiesel komersil.

\section{Materi dan Metode}

Tempat dan Waktu Pelaksanaan

Penelitian dilaksanakan di

Laboratorium Pendidikan Fakultas Perikanan dan Kelautan Universitas Airlangga Surabaya, Laboratorium Teknologi Minyak Bumi, Gas dan Batu Bara Fakultas Teknik Universitas Gajah Mada, Yogyakarta. pada bulan Mei-Juni 2014. Materi Penelitian

Alat Penelitian dan Bahan Penelitian

Peralatan yang digunakan antara lain buret, tabung reaksi $10 \mathrm{ml}$, soxhlet, flat bottom, beaker glass, botol, sumbu, magnetic stirer, heater, gelas ukur, mikro pipet $(0,1 \mathrm{ml}$ dan 1 $\mathrm{ml})$, termometer, corong dan plastik, corong, $\mathrm{pH}$ meter, thermometer, beaker glass, blender, timbangan, timer dan pemantik api.

Bahan-bahan yang digunakan adalah

Eucheuma denticulatum diperoleh dari
Kabupaten Sumenep, Madura dan minyak ikan lemuru diambil dari pabrik pengolahan tepung ikan yang ada di Banyuwangi, n-hexane, $\mathrm{KOH}($ Katalis) dan metanol.

Metode Penelitian

Penelitian ini dilakukan dengan mengamati dan membandingkan titik nyala, titik beku dan viskositas masing-masing jenis biodiesel. Metode yang digunakan dalam penelitian ini adalah metode eksperimental. Metode eksperimental merupakan suatu usaha terencana untuk mengungkapkan fakta-fakta baru atau menguatkan teori baru bahkan membantah hasil-hasil penelitian yang telah ada (Srigandono, 1987 dalam Mufarihin dkk., 2012).

Prosedur Penelitian

Pengeringan Rumput Laut

Rumput laut terlebih dahulu dicuci dengan menggunakan air tawar untuk menghilangkan kadar garam. Pencucian dilakukan hingga pasir yang menempel pada bahan sudah bersih. Setelah dicuci bersih, rumput laut dikeringkan dengan cara dianginanginkan hingga rumput laut menjadi kering. Pengeringan dilakukan selama satu minggu. Pengambilan Minyak

Rumput laut yang telah dikeringkan terlebih dahulu diekstraksi untuk diambil kandungan minyaknya agar bisa diolah menjadi biodiesel. Menurut Surya (2006), isolasi minyak alga dapat diperoleh dengan metode soxhletasi. Soxhletasi merupakan penyarian secara berkesinambungan, cairan penyari dipanaskan sehingga menguap, uap cairan penyari terkondensasi menjadi molekul-molekul air oleh pendingin balik dan turun menyari simplisia dalam klonsong dan selanjutnya masuk kembali kedalam labu (Tobo, 2001), cairan atau pelarut yang digunakan pada proses soxhletasi rumput laut adalah $n$-hexane $250 \mathrm{~mL}$.

Eucheuma denticulatum kering dimasukkan ke dalam kantung ekstraksi soxhlet yang dilapisi kertas saring dengan takaran $30 \mathrm{~g}$. Soxhlet dinyalakan dalam suhu $82^{\circ} \mathrm{C}$ selama 3 jam hingga didapatkan minyak rumput laut. Setelah sari minyak diambil, dilakukan pemanasan pada suhu $50-55^{\circ} \mathrm{C}$ untuk memisahkan $n$-hexane dengan minyaknya.

Transterifikasi

Minyak rumput laut hasil dari proses ekstraksi diletakkan dalam beker glass dan dipanaskan dengan menggunakan heater. Pada proses transesterifikasi, minyak rumput laut dicampur dengan larutan methanol sebanyak $40 \%$ yang sebelumnya sudah dicampur dengan $\mathrm{KOH} 2 \%$ sebagai katalis. Kemudian dimasukkan ke dalam reaktor untuk dipanaskan, 
suhu proses pemanasan dijaga pada suhu $60^{\circ} \mathrm{C}$ selama 1 jam sambil diaduk dengan menggunakan magnetic stirrer. Dari campuran ini akan diperoleh dua zat dengan berat jenis yang berbeda, yaitu gliserin dan metil ester. Hasil samping berupa gliserin dipisahkan dan dibuang, sehingga metil ester yang tersisa adalah produk utama yang digunakan sebagai biodiesel.

\section{Uji Analisis Biodiesel}

Minyak yang sudah ditransesterifikasi dilakukan uji analisis biodiesel yang meliputi uji titik nyala, titik beku dan viskositas. Uji tersebut dilakukan dengan bantuan panelis yang diberi kuisioner untuk melakukan penilaian atau scoring, sebelum dilakukan uji di laboratorium terhadap sampel biodiesel yang diujikan. Pengujian dilakukan di Laboratorium Teknologi Minyak Bumi, Gas dan Batu Bara Fakultas Teknik Universitas Gajah Mada guna memperoleh nilai kuantitatif dari uji viskositas, titik nyala, dan titik beku. Perlakuan yang diujikan hanya P0, P1 dan P5 sehingga dilakukan konversi nilai kuantitatif tersebut guna mengetahui nilai kuantitatif dari perlakuan yang lain.

Parameter Penelitian

Parameter utama yang diamati adalah titik nyala, titik beku dan viskositas dari masing-masing biodiesel dan kombinasi antara biodiesel komersil dengan minyak ikan dan juga kombinasi antara biodiesel komersil dengan rumput laut.

Analisis Data

Analisis data yang digunakan adalah uji nonparametrik dengan uji Friedman. Uji tersebut dilakukan untuk mengetahui peringkat dari masing-masing perlakuan yang diujikan. Kemudian dilanjutkan dengan uji Wilcoxon untuk mengetahui perbedaan dari tiap masingmasing perlakuan. Data yang dianalisa adalah titik nyala dan titik beku. Analisis data dengan menggunakan bantuan perangkat lunak SPSS 16.0 for Windows. Sedangkan pada parameter viskositas hanya dari hasil uji dari laboratorium sehingga langsung dapat dibandingkan.

\section{Hasil dan Pembahasan}

Titik nyala Biodiesel E. denticulatum dan Biodiesel Minyak Ikan Lemuru

Tabel 1. Hasil Uji Panelis dan Konversi Titik Nyala Biodiesel E. denticulatum dan Biodiesel Minyak ikan lemuru

\begin{tabular}{cccc}
\hline Perlakuan & $\begin{array}{c}\text { Rata-rata Skor } \\
\text { Uji Panelis }\end{array}$ & $\begin{array}{c}\text { Rata-rata Konversi Analisis } \\
\text { Laboratorium Titik Nyala } \\
\left({ }^{\circ} \mathrm{C}\right)\end{array}$ & $\begin{array}{c}\text { Konversi Analisis Uji } \\
\text { Panelis }\end{array}$ \\
\hline P0 & $3.00^{\mathrm{c}}$ & $62,5^{\circ} \mathrm{C}$ & 1 detik \\
P1 & $3.70^{\mathrm{a}}$ & $26^{\circ} \mathrm{C}$ & 0,6 detik \\
P2 & $3.29^{\mathrm{b}}$ & $35,12^{\circ} \mathrm{C}$ & 0,7 detik \\
P3 & $2.92^{\mathrm{c}}$ & $35,12^{\circ} \mathrm{C}$ & 0,7 detik \\
P4 & $2.96^{\mathrm{c}}$ & $53,37^{\circ} \mathrm{C}$ & 0,9 detik \\
P5 & $2.82^{\mathrm{d}}$ & $26^{\circ} \mathrm{C}$ & 0,5 detik \\
P6 & $3.96^{\mathrm{a}}$ & $26^{\circ} \mathrm{C}$ & 0,5 detik \\
P7 & $2.63^{\mathrm{e}}$ & $40,6^{\circ} \mathrm{C}$ & 0,7 detik \\
P8 & $2.93^{\mathrm{c}}$ & $47,9^{\circ} \mathrm{C}$ & 0,8 detik \\
\hline
\end{tabular}

Keterangan : P0 : Biodiesel komersil

P1 : Biodiesel Eucheuma denticulatum $100 \%$

P2 : Biodiesel Eucheuma denticulatum 75\% + Biodiesel komersil 25\%

P3 : Biodiesel Eucheuma denticulatum 50\% + Biodiesel komersil 50\%

P4 : Biodiesel Eucheuma denticulatum 25\% + Biodiesel komersil $75 \%$

P5 : Biodiesel Sardinella oil $100 \%$

P6 : Biodiesel Sardinella oil 75\% + Biodiesel komersil 25\%

P7 : Biodiesel Sardinella oil 50\% + Biodiesel komersil 50\%

P8 : Biodiesel Sardinella oil 25\% + Biodiesel komersil 75\%

Skor 1 : Tidak Nyala

Skor 2 : Nyala api merah redup

Skor 3 : Nyala api merah dengan asap hitam

Skor 4 : Nyala api merah kebiruan

Skor 5 : Nyala api biru

Superskrip yang berbeda pada kolom yang sama menunjukkan terdapat

perbedaan yang nyata $(\mathrm{P}<0,05)$ 
Dari hasil uji panelis diketahui yang memiliki titik nyala tertinggi adalah $P 6\left(26^{\circ} \mathrm{C}\right)$, yang merupakan biodiesel Sardinella oil $75 \%+$ biosolar $25 \%$ dengan waktu rata-rata penyulutan 0,5 detik. Biodiesel tersebut menghasilkan nyala api biru hingga merah kebiruan. Dari uji statistik tersebut dapat dilihat P6 (Biodiesel Sardinella oil 75\% + Biosolar $25 \%$ ) adalah perlakuan tertinggi $(3,96)$ namun tidak berbeda nyata terhadap P1 (Biodiesel Eucheuma denticulatum 100 \%) 3,70. Sedangkan P7 (Biodiesel Sardinella oil $50 \%$ + Biosolar 50\%) merupakan perlakuan terendah $(2,63)$ dan berbeda nyata terhadap P5 (Biodiesel Sardinella oil 100 \%) 2,82.

Dari hasil penelitian, dilakukan konversi dari satuan waktu (detik) menjadi suhu $\left({ }^{\circ} \mathrm{C}\right)$ agar bisa dibandingkan dengan standart SNI. Dari hasil konversi diketahui bahwa P4 (Biodiesel E. denticulatum 25\% + Biosolar $75 \%$ ) yang memiliki titik nyala tertinggi dengan suhu $53,37^{\circ} \mathrm{C}$, sementara P1 (biodiesel $E$. denticulatum 100\%), P5 (biodiesel minyak ikan lemuru 100\%) dan P6 (biodiesel minyak ikan lemuru $75 \%$ ) memiliki titik nyala terendah dengan suhu $26^{\circ} \mathrm{C}$.
Titik Beku Biodiesel E. Denticulatum dan Biodiesel Minyak Ikan Lemuru

Dari hasil uji panelis diketahui yang memiliki titik beku terendah adalah $P 1\left(-33^{\circ} \mathrm{C}\right)$, yaitu biodiesel rumput laut Eucheuma denticulatum $100 \%$ dengan membutuhkan waktu 135 menit untuk dapat membeku total. Biodiesel tersebut ketika dibekukan dalam waktu 60 menit masih dalam kondisi cair. Dari uji statistik tersebut dapat dilihat bahwa P1 (Biodiesel Eucheuma denticulatum 100 \%) adalah perlakuan tertinggi $(4,93)$ yang berbeda sangat nyata terhadap P2 (Eucheuma denticulatum 75\% + Biosolar 25\%) 4,33 dan P3 (Biodiesel Eucheuma denticulatum 50\% + Biosolar 50\%) 4,18. Sedangkan perlakuan terendah adalah P5 (Biodiesel Sardinella oil 100 \%) 1,18 yang berbeda sangat nyata terhadap P6 (Biodiesel Sardinella oil 75\% + Biosolar 25\%) 2,07 .

Dari hasil penelitian, dilakukan konversi dari satuan waktu (detik) menjadi suhu $\left({ }^{\circ} \mathrm{C}\right)$ agar bisa membandingkan dengan standart SNI. Dari hasil konversi diketahui bahwa P1 yaitu biodiesel E. denticulatum $100 \%$ memiliki titik beku terendah dengan suhu $-33^{\circ} \mathrm{C}$.

Tabel 2. Hasil Uji Panelis dan Konversi Titik Beku Biodiesel E. denticulatum dan Biodiesel Minyak ikan lemuru

\begin{tabular}{cccc}
\hline Perlakuan & $\begin{array}{c}\text { Rata-rata Skor } \\
\text { Uji Panelis }\end{array}$ & $\begin{array}{c}\text { Rata-rata Konversi Analisis } \\
\text { Laboratorium Titik Beku } \\
\left({ }^{\circ} \mathrm{C}\right)\end{array}$ & $\begin{array}{c}\text { Konversi Analisis Uji } \\
\text { Panelis }\end{array}$ \\
\hline P0 & $4.00^{\mathrm{c}}$ & $-3^{\circ} \mathrm{C}$ & 70 menit \\
P1 & $4.93^{\mathrm{a}}$ & $-33^{\circ} \mathrm{C}$ & 135 menit \\
P2 & $4.33^{\mathrm{b}}$ & $-28^{\circ} \mathrm{C}$ & 120 menit \\
P3 & $4.18^{\mathrm{bc}}$ & $-19,15^{\circ} \mathrm{C}$ & 105 menit \\
P4 & $4.04^{\mathrm{c}}$ & $-9,92^{\circ} \mathrm{C}$ & 85 menit \\
P5 & $1.18^{\mathrm{f}}$ & $-3^{\circ} \mathrm{C}$ & 45 menit \\
P6 & $2.07^{\mathrm{e}}$ & $-3^{\circ} \mathrm{C}$ & 50 menit \\
P7 & $2.26^{\mathrm{e}}$ & $-3^{\circ} \mathrm{C}$ & 55 menit \\
P8 & $3.11^{\mathrm{d}}$ & $-3^{\circ} \mathrm{C}$ & 65 menit \\
\hline
\end{tabular}

Keterangan : P0 : Biodiesel komersil

P1 : Biodiesel Eucheuma denticulatum $100 \%$

P2 : Biodiesel Eucheuma denticulatum 75\% + Biodiesel komersil 25\%

P3 : Biodiesel Eucheuma denticulatum 50\% + Biodiesel komersil 50\%

P4 : Biodiesel Eucheuma denticulatum 25\% + Biodiesel komersil 75\%

P5 : Biodiesel Sardinella oil $100 \%$

P6 : Biodiesel Sardinella oil 75\% + Biodiesel komersil $25 \%$

P7 : Biodiesel Sardinella oil 50\% + Biodiesel komersil 50\%

P8 : Biodiesel Sardinella oil 25\% + Biodiesel komersil $75 \%$

Skor 1 : Membeku total

Skor 2 : Mulai membeku

Skor 3 : Terdapat titik kristal pada sampel uji

Skor 4 : Terdapat titik embun pada tabung reaksi

Skor 5 : Masih encer

Superskrip yang berbeda pada kolom yang sama menunjukkan terdapat perbedaan yang nyata $(\mathrm{P}<0,05)$ 
Tabel 3. Hasil Uji Panelis dan Konversi Viskositas Biodiesel E. denticulatum dan Biodiesel Minyak ikan lemuru

\begin{tabular}{ccc}
\hline Perlakuan & $\begin{array}{c}\text { Rata-rata Konversi Analisis Laboratorium } \\
\text { Viskositas }\left(\mathrm{mm}^{2} / \mathrm{s}\right)\end{array}$ & Konversi Analisis Uji Panelis \\
\hline P0 & 3,26 & 46 detik \\
P1 & 22,65 & 74,3 detik \\
P2 & 17,71 & 67,1 detik \\
P3 & 12,37 & 59,3 detik \\
P4 & 6,89 & 51,3 detik \\
P5 & 13,66 & 70,7 detik \\
P6 & 7,68 & 56,5 detik \\
P7 & 5,57 & 52,3 detik \\
P8 & 4,02 & 48,2 detik \\
\hline
\end{tabular}

Keterangan : P0 : Biodiesel komersil

P1 : Biodiesel Eucheuma denticulatum $100 \%$

P2 : Biodiesel Eucheuma denticulatum 75\% + Biodiesel komersil 25\%

P3 : Biodiesel Eucheuma denticulatum 50\% + Biodiesel komersil 50\%

P4 : Biodiesel Eucheuma denticulatum 25\% + Biodiesel komersil $75 \%$

P5 : Biodiesel Sardinella oil $100 \%$

P6 : Biodiesel Sardinella oil 75\% + Biodiesel komersil 25\%

P7 : Biodiesel Sardinella oil 50\% + Biodiesel komersil 50\%

P8 : Biodiesel Sardinella oil 25\% + Biodiesel komersil $75 \%$

Sedangkan biodiesel yang memiliki titik beku tertinggi adalah P5, P6, P7 dan P8 yang memiliki titik beku yang sama yaitu $-3^{\circ} \mathrm{C}$.

Viskositas Biodiesel E. denticulatum dan Biodiesel Minyak Ikan Lemuru

Dari hasil uji panelis diketahui yang memiliki viskositas terendah adalah $P 0 \quad(3,26$ $\left.\mathrm{mm}^{2} / \mathrm{s}\right)$, yaitu biodiesel komersil yang merupakan variabel kontrol dalam penelitian ini dengan membutuhkan waktu 46 detik untuk melewati buret. Sifat bahan cair ini ketika dialirkan terlihat encer. Sedangkan yang memiliki viskositas tertinggi adalah P1 $(22,65$ $\mathrm{mm}^{2} / \mathrm{s}$ ), yaitu biodiesel rumput laut Eucheuma denticulatum $100 \%$ dengan membutuhkan waktu 74,3 detik untuk melewati buret. Sifat bahan cair ini ketika dialirkan terlihat encer. Hasil uji statistik dengan uji Friedman pada Lampiran 2 menunjukan bahwa nilai signifikansi lebih kecil dari 0,01, hal tersebut menunjukan bahwa terdapat perbedaan yang sangat nyata antar perlakuan $(P<0,01)$. Dari uji statistik tersebut dapat dilihat bahwa $P O$ adalah perlakuan terbaik namun tidak berbeda nyata terhadap P3, P6, P2, P7 dan P4. Sedangkan $P 1$ yang merupakan perlakuan terendah tidak berbeda nyata terhadap P4, P5 dan P8 yang sama-sama memiliki nilai viskositas tinggi.

Dari hasil penelitian tersebut dilakukan konversi dari satuan waktu (detik) menjadi satuan viskositas kinematik $\left(\mathrm{mm}^{2} / \mathrm{s}\right)$ agar bisa dibandingkan dengan standart SNI.
P8 (biodiesel minyak ikan lemuru 25\%) memiliki viskositas terendah dengan nilai viskositas kinematik 4,02 $\mathrm{mm}^{2} / \mathrm{s}$ dan $P 1$ (biodiesel E. denticulatum 100\%) memiliki viskositas tertinggi dengan nilai viskositas kinematik 22,65 $\mathrm{mm}^{2} / \mathrm{s}$.

Hasil Nilai Konversi Biodiesel E. denticulatum, Sardinella oil dan Biosolar

Dari hasil nilai konversi biodiesel pada Tabel 4 dapat dilihat bahwa dari seluruh perlakuan, yang memiliki titik nyala tertinggi adalah P4 (biodiesel E. denticulatum 25\%) dengan nilai titik nyala $53,37^{\circ} \mathrm{C}$. Perlakuan yang memiliki titik beku terendah adalah perlakuan P1 yaitu biodiesel rumput laut $E$. denticulatum $100 \%$ dengan suhu membeku $-33^{\circ} \mathrm{C}$. Perlakuan yang memiliki viskositas terendah adalah P8 yaitu biodiesel minyak ikan lemuru 25\% + biosolar $75 \%$ dengan nilai viskositas kinematik $4,02 \mathrm{~mm}^{2} / \mathrm{s}$.

Penelitian ini menggunakan tiga parameter uji biodiesel yaitu titik nyala, titik beku dan viskositas. Titik nyala (flash point) merupakan angka yang menyatakan suhu terendah dari bahan bakar minyak dapat terbakar jika permukaan minyak tersebut didekatkan dengan nyala api (Siswani, 2012).

Titik nyala biodiesel dari P4 (biodiesel E. denticulatum $25 \%$ + biodiesel komersil $75 \%$ ) yang memiliki titik nyala tertinggi yaitu $53,37^{\circ} \mathrm{C}$, kemudian diikuti oleh P8 (biodiesel minyak ikan lemuru $25 \%$ + biosolar $75 \%$ ) yaitu $47,9^{\circ}$ C. Sedangkan perlakuan yang lain P1, P2, 
Tabel 4. Hasil Nilai Konversi Biodiesel E. denticulatum, Sardinella oil dan Biodiesel komersil

\begin{tabular}{|c|c|c|c|c|}
\hline & Perlakuan & $\begin{array}{c}\text { Titik Nyala } \\
\left({ }^{\circ} \mathrm{C}\right)\end{array}$ & $\begin{array}{l}\text { Titik Beku } \\
\quad\left({ }^{\circ} \mathrm{C}\right)\end{array}$ & $\begin{array}{c}\text { Viskositas } \\
\left(\mathrm{mm}^{2} / \mathrm{s}\right)\end{array}$ \\
\hline P0 & Biodiesel komersil & 62,5 & -3 & 3,26 \\
\hline $\mathrm{P} 1$ & Biodiesel Rumput Laut $100 \%$ & 26 & -33 & 22,65 \\
\hline $\mathrm{P} 2$ & Biodiesel Rumput Laut 75\% + Biosolar 25\% & 35,12 & -28 & 17,71 \\
\hline P3 & Biodiesel Rumput Laut 50\% + Biosolar 50\% & 35,12 & $-19,15$ & 12,37 \\
\hline P4 & Biodiesel Rumput Laut 25\% + Biosolar 75\% & 53,37 & $-9,92$ & 6,89 \\
\hline P5 & Biodiesel Minyak Ikan $100 \%$ & 26 & -3 & 13,66 \\
\hline P6 & Biodiesel Minyak Ikan 75\% + Biosolar 25\% & 26 & -3 & 7,68 \\
\hline P7 & Biodiesel Minyak Ikan 50\% + Biosolar 50\% & 40,6 & -3 & 5,57 \\
\hline \multirow[t]{3}{*}{ P8 } & Biodiesel Minyak Ikan 25\% + Biosolar 75\% & 47,9 & -3 & 4,02 \\
\hline & Standart SNI Biodiesel & $\begin{array}{l}\text { Minimal } \\
100\end{array}$ & $\begin{array}{l}\text { Titik tuang } \\
\leq 18\end{array}$ & $2,3-6,0$ \\
\hline & Standart SNI Biosolar & $\begin{array}{l}\text { Minimal } \\
60\end{array}$ & $\begin{array}{l}\text { Titik tuang } \\
\leq 18\end{array}$ & $2,0-6,0$ \\
\hline
\end{tabular}

$\mathrm{P} 3, \mathrm{P} 5, \mathrm{P} 6$, dan $\mathrm{P} 7$ nilai titik nyalanya di bawah $40^{\circ} \mathrm{C}$. Perlakuan $\mathrm{P} 4\left(53,37^{\circ} \mathrm{C}\right)$ dan $\mathrm{P} 8\left(47,9^{\circ} \mathrm{C}\right)$ nilai titik nyalanya tertinggi dari perlakuan yang lain, tetapi nilai tersebut belum memenuhi standar yang sesuai dengan standar SNI biosolar yang ditetapkan oleh pemerintah yaitu memiliki nilai titik nyala minimal $60^{\circ} \mathrm{C}$. Nilai titik nyala dari biodiesel P4 tersebut juga tidak memenuhi syarat SNI 04-7182-2006 yang justru menetapkan nilai minimal yang lebih tinggi dari SNI biosolar yaitu nilai titik nyala minimal $100^{\circ} \mathrm{C}$.

Dari penelitian tersebut dapat dikatakan biodiesel minyak ikan lemuru yang memiliki titik nyala tertinggi di antara biodiesel minyak ikan lemuru lainnya adalah $\mathrm{P} 8$ yaitu biodiesel campuran minyak ikan lemuru $25 \%+$ biosolar $75 \%$ dengan nilai titik nyala $47,9^{\circ} \mathrm{C}$.

Dari hasil penelitian menunjukkan bahwa semakin banyak penambahan campuran biosolar ke biodiesel dapat menyebabkan titik nyala semakin tinggi. Menurut Setiawati (2012) Titik nyala mengindikasikan tinggi rendahnya volatilitas dan kemampuan untuk terbakar dari suatu bahan bakar. Volatilitas adalah kecenderungan suatu bahan untuk menguap (Lestari, 2010). Dari hasil penelitian menunjukkan bahwa biodiesel $E$. denticulatum dan minyak ikan lemuru memiliki volatilitas yang tinggi sehingga mudah terbakar.

Selain titik nyala, parameter yang diuji adalah titik beku. Dimana pada titik beku menurut Knothe (2005) permasalahan pada aliran bahan bakar terjadi pada temperatur diantara titik kabut (cloud point) dan titik tuang (pour point), yaitu pada saat titik titik kristal yang terbentuk mulai mengganggu proses filtrasi bahan bakar pada mesin sehingga perlu adanya penelitian pada parameter titik beku tersebut.

Dari hasil penelitian menunjukan bahwa biodiesel $E$. denticulatum memiliki titik beku yang sangat rendah dan sudah sesuai dengan standar SNI yaitu maksimal $0^{\circ} \mathrm{C}$. Hal ini menunjukan bahwa biodiesel $E$. denticulatum merupakan biodiesel yang dapat diproduksi dan dikomersilkan pada negara-negara yang memiliki iklim dingin karena titik bekunya yang sangat rendah. Perlakuan P1 (biodiesel $E$. denticulatum 100\%) merupakan biodiesel rumput laut yang memiliki titik beku terendah di antara biodiesel P2, P3 dan P4 dengan nilai titik beku yaitu $-33^{\circ} \mathrm{C}$.

Dari hasil penelitian menunjukan bahwa semua perlakuan biodiesel dari minyak ikan lemuru memiliki titik beku yang rendah dan sudah sesuai dengan standar SNI yaitu maksimal $0^{\circ} \mathrm{C}$. Sehingga biodiesel minyak ikan lemuru merupakan biodiesel yang dapat diproduksi dan dijual pada negara-negara yang memiliki iklim dingin karena titik bekunya yang rendah.

Selain parameter uji titik nyala, titik beku dan viskositas juga merupakan salah satu parameter penting. Viskositas adalah suatu angka yang menyatakan besarnya hambatan dari suatu bahan cair untuk mengalir atau ukuran dari besarnya tahanan geser dari cairan. Semakin tinggi viskositasnya, semakin kental 
dan semakin sukar bahan tersebut mengalir (Demirbas, 2008).

Berdasarkan penelitian tersebut biodiesel $E$. denticulatum yang memiliki nilai viskositas terbaik adalah P8 dengan nilai viskositas kinematik yaitu $4,02 \mathrm{~mm}^{2} / \mathrm{s}$. Nilai tersebut sesuai dengan syarat SNI biodiesel, SNI biosolar maupun standar viskositas biodiesel Amerika (ASTM D6751-12). Sedangkan perlakuan yang lain memiliki nilai viskositas yang lebih tinggi dari P8 dan melebihi syarat SNI biodiesel.

Apabila dilihat dari nilai titik beku dan viskositas biodiesel yang memiliki nilai terbaik pada biodiesel minyak ikan lemuru adalah P8 yaitu biodiesel minyak ikan lemuru $25 \%$ dicampur dengan biosolar $75 \%$ dengan nilai titik beku yaitu $-3^{\circ} \mathrm{C}$ dan viskositas $4,02 \mathrm{~mm} / \mathrm{s}$. Nilai tersebut sudah memenuhi standard SNI 04-7182-2006. Namun seluruh perlakuan dari penelitian ini tidak ada satupun perlakuan yang memenuhi standard titik nyala SNI biodiesel, SNI biosolar maupun standard biodiesel Amerika (ASTM D6751-12). Jadi dapat dikatakan bahwa P1, P2, P3, P4, P5, P6, P7 dan P8 memiliki tingkat keamanan yang rendah dalam penanganan dan penyimpanan karna sifat bahan mudah terbakar.

Hasil dari penelitian ini masih belum dapat dikatakan bahwa perlakuan P8 bisa dijadikan bahan bakar karena penelitian ini hanya menguji tiga parameter saja, sedangkan parameter uji biodiesel ada 17 parameter antara lain yaitu angka setana, residu karbon, kandungan air, sulfur, kandungan abu dan lainlain.

\section{Kesimpulan}

Minyak rumput laut Eucheuma denticulatum dan minyak ikan lemuru dapat dijadikan pilihan alternatif bahan pembuatan biodiesel. Berdasarkan penelitian dilihat dari nilai viskositas dan titik beku dapat dikatakan hasil yang terbaik dari semua perlakuan adalah P8 yaitu biodiesel minyak ikan lemuru $25 \%$ dengan biosolar 75\%. P8 memiliki spesifikasi titik beku $-3^{\circ} \mathrm{C}$, viskositas $4,02 \mathrm{~mm}^{2} / \mathrm{s}$, sedangkan titik nyalanya $47,9{ }^{\circ} \mathrm{C}$ masih jauh dibawah standar SNI biodiesel.

\section{Daftar Pustaka}

Atmadja, W. S., A. Kadi., Sulistijo dan Rahmaniar S. 1996. Pengenalan Jenis Jenis Rumput Laut Indonesia. Puslitbang Oseanologi LIPI. Jakarta. 92 hal.

Aziz, I. 2010. Uji Performance Mesin Diesel Menggunakan Biodiesel dari Minyak
Goreng Bekas .http : // webcache. googleusercontent.com/ search? $\mathrm{q}=$ cache:L3DdlyFRXXUJ:journal.uinj kt.ac.id/index.php/valensi/article/downl oad $/ 241 / 156+\& c d=2 \& h l=$ en $\& c t=$ clnk. hal. 2-3.

Darmanto, S., Ireng, S.A., 2006, Analisa Biodiesel Minyak Kelapa sebagai Bahan Bakar Alternatif Minyak Diesel, Traksi 4(2):64

Demirbas, A. 2008. Biodiesel a Realistic Fuel Alternative for Diesel Engines. Springer-Verlag London Limited. Pages 99-114.

Handayani, S. P. 2010. Pembuatan Biodiesel dari Minyak Ikan dengan Radiasi Gelombang Mikro. Skripsi. Jurusan Kimia. Fakultas Matematika dan Ilmu Pengetahuan Alam. Universitas Sebelas Maret. Surakarta. hal. 1-12.

Kusriningrum. 2012. Perancangan Percobaan. Fakultas Kedokteran Hewan. Universitas Airlangga. Surabaya. hal. 1 dan 43.

Knothe, G. 2005. Dependence of Biodiesel Fuel Properties on the Structure of Fatty Acid Alkyl Esters. Fuel Processing Technology. pp.86.

Lestari, E. 2010. Presentase Produk Etanol dari Distilasi Etanol-Air dengan Distribute Control System (DCS) pada Berbagai Konsentrasi Umpan. Skripsi. Program Diploma. Fakultas Teknik. Universitas Diponegoro. Semarang. 1 hal.

Mufarihin, A., D.R. Lukiwati dan Sutarno. 2012. Pertumbuhan dan Bobot Bahan Kering Rumput Gajah dan Rumput Raja pada Perlakun Aras yang Berbeda. Jurnal. Anime Agricluture Journal. Vo. 1. No. 2. 6 hal.

Murni. 2010. Kaji Eksperimental Pengaruh Temperatur Biodiesel Minyak Sawit terhadap Performansi Mesin Diesel Direct Injection Putaran Konstan. Tesis. Program Studi Magister Teknik Mesin. Program Pascasarjana. Universitas Diponegoro. 42 hal.

Murniati, R. 2011. Karakteristik Biodiesel dari Minyak Jelantah Hasil Fisisorpsi Zeolit Alam Teraktivasi. Skripsi. Jurusan Fisika. Fakultas Matematika dan Ilmu Pengetahuan Alam. Universitas Andalas. Padang. hal. 2-4

Murtidjo, B. A. 2001. Beberapa Metode Pengolahan Tepung Ikan. Yogyakarta: Penerbit Kanisius.16 hal.

Rahayu, M. 2007. Teknologi Proses Produksi Biodiesel. Prospek Pengembangan Bio- 
fuel sebagai Substitusi Bahan Bakar Minyak. 17 hal.

Saputro, D. R., A. Ridlo dan I. Widowati. 2012. Kajian Rumput Laut Sargassum duplicatum J. G. Agardh sebagai Penghasil Bioetanol dengan Proses Hidrolisis Asam dan fermentasi. Journal of Marine Research. Volume 1, Nomor 2, Tahun 2012, Halaman 145151. 2 hal.

Setiawati, E., Fatmir, E. 2012.Teknologi Pengolahan Biodiesel dari Minyak Goreng Bekas dengan Teknik Mikrofiltrasi dan Transesterifikasi sebagai Alternatif Bahan Bakar Mesin Diesel. Balai Riset dan Standardisasi Industri Banjarbaru. Jurnal Riset Industri Vol. VI No. 2, Hal. 117-118
Siswani, E. D., S. Kristianingrum dan Suwardi. 2012. Sintesis dan Karakteristik Biodiesel dari Minyak Jelantah pada Berbagai Waktu dan Suhu. Paper disampaikan dalam Seminar Nasional MIPA di FMIPA UNY. hal. 10.

Tobo.F, 2001, Buku Pegangan Laboratorium Fitokimia I, Laboratorium Fitokimia. Jurusan Farmasi. Unhas. Makassar. 18 hal. 